\title{
Voluntarism as an investment in human, social and financial capital: evidence from a farmer-to-farmer extension program in Kenya
}

\author{
Evelyne Kiptot $\cdot$ Steven Franzel
}

Accepted: 15 May 2013/Published online: 6 August 2013

(C) Springer Science+Business Media Dordrecht 2013

\begin{abstract}
A decline in public sector extension services in developing countries has led to an increasing emphasis on alternative extension approaches that are participatory, demand-driven, client-oriented, and farmer centered. One such approach is the volunteer farmer-trainer (VFT) approach, a form of farmer-to-farmer extension where VFTs host demonstration plots and share information on improved agricultural practices within their community. VFTs are trained by extension staff and they in turn train other farmers. A study was conducted to understand the rationale behind the decisions of smallholder farmers to volunteer their time and resources to train other farmers without pay and to continue volunteering. Data were gathered through focus group discussions and individual interviews involving 99 VFTs. Findings of the study showed that VFTs were motivated by a combination of personal and community interests that were influenced by religious beliefs, cultural norms, and social and economic incentives. Altruism, gaining knowledge and skills, and social benefits were the most frequently mentioned motivating factors for becoming VFTs.3 years after starting, the income earned from selling associated inputs and services was also a main motivating factor. There were no significant differences between motivating factors for men and women VFTs. The findings point to the fact that VFTs work effectively without being paid, but investments in human, social, and financial capital are crucial to keeping them motivated. These factors are key to ensuring the sustainability of farmer-to-farmer extension programs beyond the projects' lifespan.
\end{abstract}

E. Kiptot $(\bowtie) \cdot$ S. Franzel

World Agroforestry Centre (ICRAF), United Nations Avenue,

Gigiri, P.O Box 30677-00100, Nairobi, Kenya

e-mail: ekiptot@yahoo.com; e.kiptot@cgiar.org
Keywords Farmer-to-farmer extension - Gender . Volunteer farmer trainers - Motivation . Human capital · Social capital · Financial capital
Abbreviations
DFBA Dairy farmer business association
DMG Dairy management group
EADD East Africa Dairy Development
NGO Non-governmental organization
VFT Volunteer farmer trainer

\section{Introduction}

Public sector extension services in developing countries have over the last decade been experiencing a transformative process from the linear model of technology transfer to the more pluralistic demand-driven extension (Davis 2008). Despite the transformation, extension in Africa is still faced with many challenges, which have been accelerated by structural adjustment reforms aimed at reduced public spending. Some of the challenges include low budgetary allocation, understaffing, and low staff morale due to poor remuneration (Gautam 2000; Kiptot et al. 2006). Within this context, many extension services, including the private sector, government, non-governmental organizations (NGOs), and community-based organizations, have developed alternative extension approaches. They are advocating for participatory, demand-driven, client-oriented, and farmer-led approaches, with an emphasis on targeting women, the poor, and other disadvantaged groups. These approaches focus on farmers as the principal agents of change in their communities and enhance their learning and empowerment, thereby increasing their capacity to innovate and train other farmers. 
The role of extension officers is also changing from one of agents transmitting technical messages to facilitators who train farmers in entrepreneurship and link them to markets and credit institutions (Christoplos 2010). For these new approaches to be institutionalized in the mainstream extension service, they must demonstrate their superiority over old approaches that were abandoned for being high cost, ineffective, inefficient, and not taking into account the needs of farmers (Gautam 2000). The new approaches should be accountable to their clients, ensure sustainability, and be effective in disseminating new technologies.

One such approach is the volunteer farmer-trainer approach that is being used by the East Africa dairy development (EADD) Project in Kenya to disseminate information on livestock feed technologies to dairy farmers. Farmers' dairy organizations select VFTs among their members and the trainers agree to participate in training, host a demonstration plot, and train their fellow members. As is often the case with voluntary programs, a key challenge is to motivate VFTs. A second challenge is to ensure that women participate in and benefit from such programs because their exclusion from many extension initiatives has been widely documented (Gilbert et al. 2002; Katungi et al. 2008).

The volunteer farmer-trainer approach

The VFT approach is a form of farmer-to-farmer extension where farmers take the lead in information sharing within their community. Farmer-to-farmer extension is a more viable method of technology dissemination as it is based on the conviction that farmers can disseminate innovations more efficiently than extension agents. Farmers themselves have an in-depth knowledge of local conditions, culture, and practices, and are known by the other farmers. In addition, VFTs live in the community, speak the same language, use expressions that suit their environment, and instill confidence in their fellow farmers (Mulanda et al. 2000; Weinand 2002; Sinja et al. 2004; Lenoir 2009). Thus, VFTs are able to formulate the message in a way that can be understood better by farmers. The VFT approach is particularly suited to group-based extension approaches, in that it can have a multiplier effect because VFTs are expected to share information within their social networks and can help reduce transaction costs. Furthermore, because farmer trainers are selected by the community, they are directly accountable to the farmers who selected them, thus the group approach is able to provide a monitoring and evaluation function at no cost (De Haan 2001). In spite of the advantages of the VFT approach, there are also challenges, such as mistrust, dropouts, and lack of respect for some trainers because of their background (Weinand 2002).
The farmer-to-farmer extension approach has its origins in Guatemala in the 1970s. It is currently practiced widely in many other countries in Latin America, Asia and Africa in different forms (Weinand 2002). Farmer-to-farmer extension emerged as a reaction to the top-down transfer of technology models that left little possibility for the farmers' participation and initiative. They did not address farmers' needs, were inefficient, were biased in favor of well-to-do farmers, and extended inappropriate technologies (Gautam 2000). Such top-down approaches resulted in disinterested farmers and de-motivated extension officers (Nagel 1997). The most well-known farmer-to-farmer extension approach is the "Campesino a Campesino" movement in Nicaragua. At the center of this approach are farmer trainers, known by many different names in different countries and projects. In Nicaragua, the farmer trainers are known as promoters (Hawkensworth and Garcia Perez 2003) while the International Centre of Insect Physiology and Ecology in Kenya calls them farmer teachers (Amudavi et al. 2009). In Burkina Faso, farmer trainers are known as farmer advisors (Lenoir 2009) while in Peru they are known as farmer extension agents (Kamayoq) (Hellin and Dixon 2008). Selener et al. (1997) define farmer trainers as individuals with little or no formal education who, through a process of training, experimentation, learning, and practice, increase their knowledge and become capable of sharing it with others, functioning as extension workers.

The farmer-trainer approach differs from country to country due to the conditions under which it takes place, the organizational set up and management. Variants of the approach all have two things in common: farmer trainers are trained by external agents, and they in turn share their knowledge and skills with other farmers in the community. The role of farmer trainers varies from project to project depending on how they are selected to become trainers, their mode of operation, whether they are compensated for the time they spend training other farmers, whether they work with groups or individuals, whether they are trained as specialists in one subject or as generalists, and whether or not they work only in their own community or outside as well (Scarbourough et al. 1997). Others may train upon request or at home. The Kamayoq in Peru are paid by their fellow farmers for their services in cash, in kind, or with the promise of future help through an indigenous system known as 'ayni' (Hellin et al. 2006). In contrast, the farmer trainers in the EADD Project are volunteers and are, therefore, not paid for their services.

\section{The farmer trainers in the EADD Project}

The EADD Project is implemented by a consortium of partners led by Heifer International. The project started in 
2008 with its main objective being to double the incomes of 179,000 dairy farmers in Kenya, Uganda, and Rwanda through improved dairy production and marketing. EADD works at 21 sites in Kenya, also known as hubs managed by dairy farmer business associations (DFBAs). They are spread out across several districts of Central and Rift Valley provinces. The DFBA has several thousand members and is a vehicle to deliver services to farmers. Its benefits as a dairy hub are twofold: (1) it bulks and sells milk, providing income to farmers; and (2) it is a place where farmers can access services such as financing, technical support, or artificial insemination for their animals and, in certain instances, credit and a 'check off' system, where inputs are provided and their costs are deducted from milk revenue. DFBAs are taking over extension functions from the project, paying extension staff from the funds they generate selling milk.

The EADD's role has been to bridge the inefficiencies in the dairy value chain by addressing the factors that affect it: insufficient milk volumes, poor milk quality, inefficient production systems, seasonality and price fluctuations, fragmented markets, debilitating policies, the exclusion of women, and the ineffective utilization of youth. As a result of EADD interventions, participating farmers have begun to view their cattle as part of a dairy business opportunity and have been able to increase incomes and improve livelihoods. Milk production has also increased significantly with a few challenges in some areas where production exceeded market demand, leading to some spoilage and frustration by farmer participants. However, the problem has been addressed by ensuring proper market linkages.

The World Agroforestry Centre, the EADD partner leading the feeding systems component, initiated the VFT approach to facilitate the spread of livestock feed technologies. As of 2012, 1,443 VFTs had been selected in Kenya (Kirui and Franzel 2012). The VFTs are selected through a participatory process involving their dairy management groups (DMGs) composed of about 20 farmers, project dissemination facilitators, and the DFBAs. The selection criteria include:

- The ability to read and write;

- The ability to interpret extension material to farmers;

- Membership in a farmer organization or cooperative society working with the EADD Project;

- Being a dairy farmer;

- Having the willingness, interest, and ability to disseminate new innovations and knowledge to others without pay;

- Being a resident in the community;

- Being willing to set aside land for setting up demonstrations.
After selection, VFTs are trained in feeds and feeding systems during an intensive, two-day course. They are supported to set up demonstration plots of various feed practices, which include different grasses, fodder shrubs, and herbaceous legumes. These demonstration plots are used as training grounds. They are trained in feed conservation techniques including silage making, hay baling, and management and utilization of crop residues. Project staff visits the VFTs from time to time and organizes periodic training to improve their knowledge and skills. Some VFTs have the opportunity to participate in educational tours to innovative farms. So the big question is, in the absence of a salary, what is it that motives smallholder farmers to volunteer their time and resources to train other farmers within the community?

\section{Research on voluntarism}

Research on voluntarism is a not a new phenomenon. The body of literature on this subject is enormous in areas such as health care programs, religious organizations, and the NGO sector. However, research on voluntarism in farmerled extension programs is limited. The question regarding what induces smallholder farmers to volunteer their time and resources to train other farmers has not been adequately addressed. While economic models explaining voluntarism have been articulated (Roy and Ziemek 2000; Ziemek 2006) they cannot be generalized to smallholder farmers who rely mainly on mixed crop-livestock subsistence farming as a source of livelihood.

The main characteristic of volunteers all over the world is that they take part in an activity of their own free will and for no remuneration. For the farmers, the time spent volunteering can negatively affect the productivity on their own farms and is, thus, not economically rational. A few studies have been undertaken in Africa to understand the rationale of voluntarism, such as those by Kawash (2009) who studied the motivation of VFTs in Malawi, and Uny (2008) who examined factors contributing to community volunteers' participation in a nursery feeding project for orphans. The findings by Uny (2008) pointed to a mix of intrinsic motivations and the building of social capital. Kawash (2009) showed that in addition to social capital, other motivations for volunteering include gaining knowledge and skills (human capital) and income from better farming practices (financial capital). Can these findings also apply to VFTs in the EADD Project in spite of the fact that there are differences in context and subject matter? The context within which a particular motivational incentive manifests itself is crucial. Certain motivational incentives will only suffice under particular circumstances and these vary in different contexts. Context in this paper describes the conditions in which a program or intervention works. Context is not in any way limited to locality; it may 
relate to systems of social relationships, to the technology and institutional settings in which VFTs operate, and may even be linked to access to markets (Kiptot 2007a). VFTs in Kenya operate within an institutional framework of the EADD Project where they are trained and receive inputs for setting up demonstration plots as incentives. The challenge in this kind of setting is how to ensure sustainability once the formal institutional framework no longer exists. The purpose of this paper is threefold. The first is to contribute to the debate on the motivations for voluntarism and explore further how human, social, and financial capitals are built as VFTs disseminate livestock feed information to other farmers within their social networks. The emphasis on human, social, and financial capitals is derived from the sustainable livelihoods framework which identifies five capital assets that enable people to carry out their livelihood strategies (Chambers and Conway 1992). The two capitals that are not explored in this paper are physical and natural. The second is to discuss costs incurred and benefits received by VFTs. The third is to provide recommendations on how to keep VFTs motivated in order to ensure the sustainability of the approach.

Data are broken down by gender to understand the differences between men and women. The paper is organized into several sections. The first section describes the VFT approach and its implementation in the EADD Project, and reviews research on motivations for voluntarism. Next the methodology and results of the study are presented, highlighting the characteristics of VFTs, factors motivating VFTs, and costs and benefits incurred from their perspective. This is followed by a discussion on how VFTs have through the course of voluntarism, invested in human, social, and financial capital. Lastly, we provide recommendations for extension services implementing such programs, focusing on ways to ensure their sustainability.

\section{Methods}

Description of study sites

We conducted this study in seven sites where VFTs had been working the longest-Kieni (Mweiga), Olkalou, Muki, Kipkaren, Kabiyet, Cheptalal, and Longisa. Study sites experience different patterns of rainfall. Central Province and south Rift Valley have a bimodal type of rainfall with the short rains falling in October to December while the long rains are in March to May. North Rift Valley has a unimodal type of rainfall with a long rainy season and a short dry season between November and February.

Dairy farming is common in all of the study sites. Feeding systems include zero grazing (cattle confined and stall fed), pure grazing, where cattle graze freely on private land in paddocks or tethered, and systems that combine the two. Pure grazing is common in the north and south Rift Valley. Zero grazing is prevalent in central Rift Valley and central Kenya. The major economic activities, apart from dairy farming in the south Rift region, are tea (Camellia sinensis (L.) Kuntze) and pyrethrum (Chrysanthemum cinerariifolium Trevir. Vis) production, while in central Kenya and central Rift Valley, the major economic activities are flowers for export, onions (Allium cepa L.), peas (Pisum sativum L.) and carrots (Daucus carota var. sativus). In the north Rift Valley, the main economic activity is maize (Zea mays L.) production.

Specific methods used in study

We used both qualitative and quantitative methods of data collection, including focus group discussions and in-depth interviews with individual VFTs.

In order to capture qualitative information about motivational incentives of VFTs, we held focus group discussions in five sites-Olkalou, Kieni (Mweiga), Cheptalal, Kipkaren, and Longisa - with 66 VFTs, of which 49 were male and 17 were female. Motivations are often hidden and cryptic and, therefore, the researchers had to engage more deeply with the respondents in an informal way in order to be able to elicit real motivations. The purpose of the discussions was threefold: (1) to build adequate rapport with the VFTs, a fundamental requirement for further in-depth interviews; (2) to gain an understanding of the perceptions of VFTs about the factors that motivate them; and (3) to collect qualitative data from the VFTs to be used in formulating a hypothesis for more in-depth interviews with individual VFTs in a formal survey to gather quantitative data. We also held group discussions in each of the five sites with groups of 5-20 VFTs to garner their perceptions about the VFT approach. Topics discussed included length of time served, distance covered, mode of transport used, number of farmers trained, technologies disseminated, costs incurred, benefits received, and factors that motivate them. Participants were about one-third female, reflecting the male-female ratio of VFTs recruited by the EADD Project.

The collection of quantitative data was through a formal survey that involved in-depth interviews with individual VFTs using a structured questionnaire. Formal surveys have often been criticized for not being able to capture the perceptions of respondents because questions are designed by researchers and, therefore, responses are to a larger extent influenced by the perspectives of the researcher (Kiptot 2007b). To overcome this limitation, we first undertook an informal exploratory survey through focus group discussions mentioned in the previous section. We formulated the questions in the structured formal survey based on the perceptions given by VFTs during the focus 
group discussions. We used the formal survey to capture quantitative data that would enable an understanding of the factors that motivate VFTs. Ranking and ratings were used. VFTs were asked to rank various motivations in order of importance or preference. In some cases, we used the pairwise matrix ranking where VFTs were asked to compare two options at a time and decide on which of the two was preferred. Rating was also done in some cases to give different options some weighting, using a 3-point Likert scale where 3 was considered highest with 1 lowest. Before administering the questionnaire, enumerators were trained to ensure they understood the questions and what was expected of them. After training, a pretest was conducted with a small sample of VFTs who were not selected for the survey.

Sampling and selection of VFTs for the study

The sample frame for the study was the 107 VFTs who were recruited and trained in 2008, the first year of the EADD Project. One-third of the VFTs were females (Kirui et al. 2009). Due to various reasons such as dropouts and illness, the study was able to include 99 VFTs. The selected VFTs were from two districts in the southern Rift Valley Province (Bomet, Konoin), three from northern Rift Valley Province (Nandi North, Uasin Gishu, Wareng), five from Central Province (Milanguni, Nyandarua Central, Kipipiri, Nyandarua South, Kieni West), and one from central Rift Valley Province (Gilgil).

\section{Data analysis}

We examined descriptive statistics, such as frequency counts, percentages, mean, and standard error of mean. Rating data was computed using mean ratings. Pairwise matrix ranking data were analyzed by computing scores for the pairwise matrix, whereby ranks were given scores as follows; $1=5,2=4,3=3,4=2$. The scores were multiplied by the frequencies and total score computed. The highest score was ranked 1 . To test statistical significance of the difference between the rankings of various options, we used the Bradley-Terry Model, which is a linear model that gives maximum likelihood of the probability that option $i$ is ranked higher than option $j$ (Bradley and Terry 1952).

\section{Results}

Demographic and socio-economic characteristics of volunteer farmer trainers

The average age of male and female VFTs interviewed was the same: 47 years (see Table 1). A majority of VFTs
(92\%) interviewed were married, $2 \%$ were widowed, and $6 \%$ were single. The overall average farm size for VFTs was 8.9 acres, considerably higher than the average farm size in the area. Male VFTs' farm size averaged 9.7 acres and was significantly greater than female VFTs' farm size, which averaged 5.8 acres $(p<0.01)$.

The overall average number of groups that VFTs belonged to was 3.0 with no statistically significant difference between male VFTs (2.9 groups) and female VFTs (3.1 groups). On average, VFTs had 11.3 years of dairy experience. Female VFTs had significantly fewer years of dairy experience ( 7.7 years on average), while males averaged 12.2 years $(p<0.10)$. Basic education has been shown to place farmers in a better position to perceive the potential benefits of improved technologies (Wanyoike et al. 2001). Importantly, VFTs should have basic education because they are required to interpret extension materials to other farmers. The average VFT had attained some level of secondary education: an average of 10.7 years of schooling. Male VFTs had an average of 11.1 years, while females had an average of 9.0 years. This difference was statistically significant at $p<0.05$.

The type of housing in Kenya is normally used as one of the indicators of wealth. Poor farmers normally have mudwalled houses with grass used as roof material. Those of average means can afford to buy corrugated iron sheets for the roof. Wealthy farmers normally have stone walls with corrugated/tiled roofs. Only $3 \%$ of VFTs could be termed poor as they had grass thatched houses. The majority (97\%) could be classified as middle income as they had houses with corrugated iron sheets. The poor are underrepresented largely because there are few who are dairy farmers; the sample was drawn from dairy farmers who are generally of average means compared to the general population. As for the type of wall material used, $29 \%$ had timber, $28 \%$ had mud walls, $16 \%$ had stone, $15 \%$ had bricks, $10 \%$ had timber off cuts, and $1 \%$ had corrugated iron sheets.

VFTs usually train farmers within their own DMGs and sometimes other groups that are outside their own villages. VFTs trained on average 2.5 times per month during the dry season and 2.3 times during the rainy season. There was, however, no statistically significant difference between female and male VFTs. Men covered more villages than women $(5.3$ vs. $2.8, p<0.1)$ perhaps because they had better access to transportation. The longest distance traveled was about $6.7 \mathrm{~km}$ and traveling was mostly on foot.

Factors that motivated farmers to become trainers

The motivating reasons for becoming VFTs were grouped into five categories: altruism, gaining knowledge/skills, 
Table 1 Demographic and socio-economic characteristics of farmer trainers interviewed

\begin{tabular}{|c|c|c|c|c|c|c|c|}
\hline \multirow[t]{2}{*}{ Variables } & \multicolumn{2}{|c|}{ All VFT $(n=99)$} & \multicolumn{2}{|c|}{ Female VFT $(n=20)$} & \multicolumn{2}{|c|}{ Male VFT $(n=79)$} & \multirow[t]{2}{*}{$T$ test } \\
\hline & Mean & SE & Mean & SE & Mean & SE & \\
\hline Age (yrs) & 46.8 & 1.0 & 46.9 & 2.0 & 46.8 & 1.2 & ns \\
\hline Land size (acres) & 8.9 & 1.1 & 5.8 & 0.9 & 9.7 & 1.4 & $* * *$ \\
\hline No. of groups & 3.0 & 0.1 & 3.1 & 0.3 & 2.9 & 0.1 & $\mathrm{~ns}$ \\
\hline No. of years of dairy experience & 11.3 & 1.1 & 7.7 & 2.1 & 12.2 & 1.1 & $*$ \\
\hline Education (years) & 10.7 & 0.3 & 9.0 & 0.7 & 11.1 & 0.3 & $* *$ \\
\hline No. of times per month VFTs train during the dry season & 2.5 & 0.11 & 2.4 & 0.26 & 2.5 & 0.13 & ns \\
\hline No. of times per month VFTs train during the rainy season & 2.3 & 1.4 & 2.4 & 0.310 & 2.3 & 0.15 & ns \\
\hline No. of villages covered outside own village & 4.8 & 0.62 & 2.80 & 0.40 & 5.3 & 0.76 & $*$ \\
\hline Longest distance covered (km) & 6.7 & 0.69 & 5.2 & 1.0 & 7.38 & 0.82 & ns \\
\hline Time (hrs) spent on dissemination activities & 1.9 & 0.10 & 1.80 & 1.2 & 1.9 & 0.9 & ns \\
\hline
\end{tabular}

$n s$ not significant

Significance level: $* p<0.10, * * p<0.05, * * * p<0.01$

income, social benefits, and project benefits (Table 2). The income category includes earning income through: (1) training other farmers either on their farms or at other locations for a fee (2) selling seeds, and (3) providing other services. The farmers knew that some experienced farmer trainers are paid by NGOs to train other farmers either on their farms or are invited to provide training to other farmers elsewhere. They believed that by becoming VFTs, they would eventually be able to earn income in such ways. The "social benefits" category includes improving one's social status, increasing social networks, and enhanced fame and popularity, which VFTs indicated might be a springboard to leadership positions within the community. Project benefits include training and going for tours and exchange visits.

Results from the formal survey provide quantitative evidence on VFTs' motivations. A high proportion of VFTs $(93 \%)$ said they were motivated to become trainers to gain knowledge of and skills in improved dairy feed technologies. This was followed by altruism (85\%) and social benefits $(76 \%)$. A substantial number of VFTs (71\%) mentioned project benefits. The desire to increase their income through the sale of seeds and charging for services was mentioned by $64 \%$ of VFTs (Table 3). To understand the importance attached to these factors, VFTs were further asked to rate the reasons that motivated them to become VFTs in order of importance. A Likert scale of 1-3 was used where $1=$ least important, $2=$ important, and $3=$ very important. The highest ratings were for gaining knowledge/skills (2.6), altruism (2.4), social benefits (2.2), and project benefits (2.2). The lowest rating was for income (2.0). The ratings corroborated the frequency results (see Table 3). On segregating data by gender, female VFTs' mean scores for altruism were slightly higher than their male counterparts while men's scores for social benefits and project benefits were slightly higher than for women. There were, however, no statistically significant differences between men and women on any of the scores.

Reasons motivating volunteer farmer trainers to continue training

While the previous section dealt with farmers' perceptions of reasons that motivated them to become VFTs, this section deals with their current motivations three years after becoming VFTs. The two main reasons mentioned by VFTs in all five sites during the focus group discussions that continue to motivate them as trainers were knowledge/ skills and income (see Table 4). VFTs noted that improved income comes from providing other farmers with services such as cow registration, ear tagging, chaff cutter hire, the sale of seeds and planting material, silage making, and hay baling. Knowledge was also said to increase productivity as mentioned by one VFT: "The knowledge I have gained has increased productivity and my income. Before I became a VFT, I used to get less than $5 \mathrm{~L}$ of milk in a day, but I now get about 40 L!" Non-tangible benefits that motivate VFTs to continue training include being kept busy: "I retired from formal employment five years ago and I had nothing to do at home. Being a VFT keeps me busy. I am even looking much younger than I was three years ago." Other social benefits are increased social status and being "famous": "Service to the community has made me become so famous. Wherever I go, farmers refer to me as Mwalimu [Kiswahili for teacher]. This recognition has also raised my social status and I am thinking of vying for a political position at the local government level." VFTs also 
Table 2 Focus group discussions on factors that motivated farmers to become trainers

\begin{tabular}{|c|c|c|c|c|c|c|}
\hline \multirow[t]{2}{*}{ Grouping variable } & \multirow[t]{2}{*}{ Motivation to become a trainer } & \multicolumn{5}{|c|}{ Study sites } \\
\hline & & Olkalou & Kieni & Cheptalal & Kipkaren & Longisa \\
\hline \multirow[t]{5}{*}{ Altruism } & Passion to bring farmers together & $\checkmark$ & & & & \\
\hline & Desire to improve local society/uplift standards & $\checkmark$ & & & $\checkmark$ & $\checkmark$ \\
\hline & Desire to help others benefit from the use of new technologies & $\checkmark$ & $\checkmark$ & & & \\
\hline & To be a role model to other farmers & $\boldsymbol{\nu}$ & $\boldsymbol{\sim}$ & & & $\checkmark$ \\
\hline & Create awareness about dairy farming & & & $\checkmark$ & & \\
\hline \multirow[t]{4}{*}{ Knowledge and skills } & To be the first to acquire new technology & & $\checkmark$ & & & \\
\hline & Improve milk production & & & & & $\boldsymbol{\alpha}$ \\
\hline & Desire to learn to conserve feed & & $\checkmark$ & $\checkmark$ & & \\
\hline & Improve livestock productivity & $\boldsymbol{\nu}$ & $\boldsymbol{\sim}$ & & & \\
\hline Income & $\begin{array}{l}\text { Desire to earn income through training farmers, sale of seeds, } \\
\text { and services }\end{array}$ & $\boldsymbol{\sim}$ & $\boldsymbol{\sim}$ & $\checkmark$ & $\checkmark$ & $\boldsymbol{V}$ \\
\hline \multirow[t]{4}{*}{ Social benefits } & Springboard to leadership position & $\checkmark$ & & & & \\
\hline & Improve social status & $\boldsymbol{\sim}$ & & & & \\
\hline & Meet different people & $\boldsymbol{\nu}$ & & & & \\
\hline & Increase social networks & $\boldsymbol{\sim}$ & & $\checkmark$ & & \\
\hline Project benefits & Opportunity for exposure through farmer exchange visits & & & $\checkmark$ & & \\
\hline
\end{tabular}

Table 3 Reasons that motivate farmer trainers to become trainers

\begin{tabular}{|c|c|c|c|c|c|c|c|}
\hline Motivation & $\begin{array}{l}\% \text { of VFTs } \\
\text { mentioning }\end{array}$ & $\begin{array}{l}\text { Mean } \\
\text { scores }\end{array}$ & SE & $\begin{array}{l}\text { Males } \\
\text { mean scores }\end{array}$ & SE & $\begin{array}{l}\text { Females } \\
\text { mean scores }\end{array}$ & $\mathrm{SE}$ \\
\hline Gain knowledge/skills & 93 & 2.6 & 0.06 & 2.6 & 0.07 & 2.6 & 0.14 \\
\hline Altruism & 85 & 2.4 & 0.08 & 2.3 & 0.09 & 2.4 & 0.20 \\
\hline Social benefits & 76 & 2.2 & 0.09 & 2.2 & 0.09 & 2.1 & 0.22 \\
\hline Project benefits & 71 & 2.2 & 0.09 & 2.2 & 0.10 & 2.0 & 0.27 \\
\hline Income & 64 & 2.0 & 0.1 & 2.0 & 0.19 & 2.0 & 0.19 \\
\hline
\end{tabular}

Rating was based on a Likert scale of 1-3 where $1=$ least important, $2=$ important, and $3=$ very important. VFTs were permitted to mention more than one motivation; hence, the percentage total is greater than 100

indicated that the impact from the training activities gives them satisfaction: "Seeing other farmers in the community improve their productivity as a result of my training gives me satisfaction. It makes me feel good." They also appreciate their increased social network: "I interact with so many people. I have established so many contacts, including you!"

The reasons given for continuing to be a VFT are similar to those for becoming a VFT, with two exceptions. First, the percentage mentioning income as a motivation increased from 64 to $88 \%$. While income ranked fifth among the most frequently mentioned reasons for becoming a VFT, it was the most frequently mentioned motivation for continuing to be a VFT (Tables 3 and 5). Second, training farmers has led to an increased demand for training which has become an important reason for VFTs to continue training. The demand for training was not mentioned as a reason for becoming a farmer trainer but it was the third most commonly cited reason for continuing training. Findings from the scores using a Likert scale of 1-3 offered similar results to those of the frequency of reasons given for continuing to be a VFT. Altruism, gaining knowledge/skills, and income received the highest scores. Mean scores were slightly higher for females than males on altruism, income, and project benefits. However, the differences were not statistically different.

Costs incurred and benefits received by volunteer farmer trainers

Focus group discussions revealed that VFTs incur several costs while undertaking their dissemination activities. 
Table 4 Focus group discussions on reasons that motivate farmers to continue being trainers

\begin{tabular}{|c|c|c|c|c|c|c|}
\hline \multirow[t]{2}{*}{ Grouping variable } & \multirow[t]{2}{*}{ Reasons } & \multicolumn{5}{|c|}{ Study sites } \\
\hline & & Olkalou & Kieni & Cheptalal & Kipkaren & Longisa \\
\hline \multirow[t]{3}{*}{ Altruism } & Contribute to development within the community & & & $\checkmark$ & & \\
\hline & Continued interest in training others & & & $\checkmark$ & & \\
\hline & Impart knowledge to family and friends & & $\checkmark$ & & & \\
\hline \multirow{5}{*}{$\begin{array}{l}\text { Gain knowledge } \\
\text { and skills }\end{array}$} & Desire to acquire more knowledge & $\boldsymbol{V}$ & $\checkmark$ & & & \\
\hline & Gain skills on new feed technologies & & & $\checkmark$ & & \\
\hline & Improved quality of the animals (genetics) and health & & & $\checkmark$ & & \\
\hline & Improve milk production & $\boldsymbol{V}$ & $\checkmark$ & $\checkmark$ & $\checkmark$ & $\boldsymbol{V}$ \\
\hline & Better returns from the farm & & & & $\checkmark$ & \\
\hline \multirow[t]{3}{*}{ Income } & Payment for services offered & & & & & $\boldsymbol{V}$ \\
\hline & Improved farm management & & & & $\checkmark$ & \\
\hline & $\begin{array}{l}\text { Improved income from services (e.g., chaff cutter hire, } \\
\text { sale of seeds, hay baling, silage making) }\end{array}$ & $\boldsymbol{\nu}$ & $\checkmark$ & $\checkmark$ & $\checkmark$ & $\boldsymbol{v}$ \\
\hline \multirow[t]{7}{*}{ Social benefits } & Become famous & & $\checkmark$ & & & \\
\hline & Keep busy and active & & $\checkmark$ & $\checkmark$ & $\checkmark$ & \\
\hline & Training others brings satisfaction & & & & & $\checkmark$ \\
\hline & Improved social status & & & $\checkmark$ & $\checkmark$ & \\
\hline & Create self-employment & & & & $\checkmark$ & \\
\hline & Opportunities to meet investors & & & $\checkmark$ & & \\
\hline & Become a model farmer in village & & $\checkmark$ & & & \\
\hline \multirow[t]{3}{*}{ Project benefits } & Opportunities for training & & & $\checkmark$ & & $\boldsymbol{V}$ \\
\hline & Given incentives by project & & & $\checkmark$ & & $\checkmark$ \\
\hline & Opportunities for farmer exchange visits & & & & $\checkmark$ & \\
\hline $\begin{array}{l}\text { Increased demand } \\
\text { for training }\end{array}$ & Demand from farmers for training & & & & & $\boldsymbol{\sim}$ \\
\hline
\end{tabular}

Table 5 Reasons that motivate volunteer farmer trainers to continue training

\begin{tabular}{|c|c|c|c|c|c|c|c|}
\hline \multirow[t]{2}{*}{ Motivation } & \multirow{2}{*}{$\begin{array}{l}\% \text { of VFTs } \\
N=99\end{array}$} & \multirow[t]{2}{*}{ Mean scores } & \multirow[t]{2}{*}{ SE } & \multicolumn{2}{|c|}{ Male VFTs $(n=79)$} & \multicolumn{2}{|c|}{ Female VFTs $(N=20)$} \\
\hline & & & & Scores & SE & Scores & SE \\
\hline Income & 88 & 2.5 & 0.085 & 2.5 & 0.09 & 2.6 & 0.18 \\
\hline Gain knowledge/skills & 87 & 2.5 & 0.068 & 2.5 & 0.78 & 2.5 & 0.17 \\
\hline Altruism & 81 & 2.5 & 0.073 & 2.5 & 0.08 & 2.6 & 0.16 \\
\hline Increased demand for training & 81 & 2.4 & 0.077 & 2.4 & 0.09 & 2.6 & 0.17 \\
\hline Social benefits & 73 & 2.2 & 0.089 & 2.2 & 0.09 & 2.2 & 0.28 \\
\hline Project benefits & 72 & 2.2 & 0.0 .97 & 2.2 & 0.10 & 2.2 & 0.24 \\
\hline
\end{tabular}

Rating was based on a Likert scale of 1-3 where $1=$ least important, $2=$ important, and $3=$ very important

These include snacks and drinks for trainees, lunch for themselves, transport, training materials, the opportunity cost of time spent training, expenses incurred using mobile phones, and maintaining their bicycles and motorcycles. In return, they receive benefits such as knowledge and skills, improved social status, confidence, fame and popularity, and increased social networks. In order to further understand the importance attached to benefits received by
VFTs, they were classified into two categories: social and financial.

\section{Social benefits}

The social benefits VFTs receive may be grouped into four categories: exposure (having an opportunity to travel, and to see and learn about new technologies), confidence, 
Table 6 A pair-wise matrix ranking of social benefits received by volunteer farmer trainers

\begin{tabular}{|c|c|c|c|c|c|c|}
\hline \multirow[t]{2}{*}{ Social benefits } & \multirow[t]{2}{*}{ Overall total score } & \multirow[t]{2}{*}{ Overall rank } & \multicolumn{2}{|c|}{ Male VFTs $(n=79)$} & \multicolumn{2}{|c|}{ Female VFTs $(n=20)$} \\
\hline & & & Total score & Rank & Total score & Rank \\
\hline Exposure & 376 & 1 & 291 & 1 & 85 & 1 \\
\hline Gaining confidence & 359 & 2 & 287 & 2 & 72 & 2 \\
\hline Increased social networks & 339 & 3 & 276 & 3 & 63 & 3 \\
\hline Improved social status & 312 & 4 & 252 & 4 & 60 & 4 \\
\hline
\end{tabular}

To compute scores for the pairwise matrix, the ranks were given scores as follows: $1=5,2=4,3=3,4=2$. The scores were multiplied by the frequencies and total score computed. The highest score was ranked 1

increased social status, and increased social networks (social structures made up of individuals or organizations that are connected by one or more specific types of interdependency, such as friendship, kinship, and common interest). Farmers ranked the social benefits they received for being a VFT in order of importance using pairwise ranking. Exposure ranked highest, followed by gaining confidence, increased social networks and improved social status (Table 6).

Interestingly, the category most frequently ranked highest was confidence, while a large number also ranked it fourth. Apparently, while a substantial number of farmers felt that gaining confidence was an important benefit, others did not. There was no difference in ranking between male and female VFTs. Further analysis was carried out using the Bradley-Terry Model to show the number of times that the row option was ranked above the column option and to test significant differences (Table 7). Although exposure ranked first overall, gaining confidence was ranked 49 times above it, improved social status 34 times, and increased social networks 36 times.

The results of the Wald test of significance, however, show that there is a high probability of exposure being ranked higher than increased social networks at $p<0.05$, exposure being ranked higher than improved social status at $p<0.001$, and gaining confidence being ranked higher than improved social status $p<0.05$ (Table 7).

Income from selling inputs and services

About half of the VFTs $(49.5 \%)$ receive income from selling services or inputs such as seed and seedlings of various feed technologies. The most important income sources were from hay fodder $(15 \%)$, chaff cutter services (14\%), silage making (13\%), Chloris gayana seeds (12\%), Calliandra calothyrsus seedlings (12\%), and ear tagging $(11 \%)$. Other services and inputs sold or rendered by less than $10 \%$ of VFTs included Sorghum bicolor seeds, Pennisetum purpureum canes, hay baling, oat seeds, and sweet potato vines. Only one farmer had received income from training other farmers, having been contracted by an NGO.

\section{Discussion}

This study analyzes systematically the motivations of VFTs. Farmers were motivated to become trainers by, in order of importance, the desire to gain knowledge and skills, altruism, social benefits, project benefits, and income from selling inputs and services. After about three years of serving, income from selling inputs and services had emerged as the most frequently mentioned motivation and a new motivation, meeting the increased demand for training, had emerged. In fact, three motivations appeared to be of about equal importance: altruism, gaining knowledge and skills, and income from selling inputs and services. These findings suggest that VFTs are motivated by personal and community interests, which support the findings by Kawash (2009) and Uny (2008). Another study by Mazancovà and Havrland (2010) on the role of motivation in extension service showed that extension workers, though not volunteers, are also motivated by personal and community interests. For VFTs, personal interests concern improving one's economic status (financial capital), building knowledge and skills (human capital), and enhancing social capital. In contrast, altruism concerns community interests and builds social capital. Below is a critical examination of how VFTs have, through the course of voluntarism, invested in human, social, and financial capital.

\section{Human capital}

According to Coleman (1988) human capital is created if new skills and capabilities make one able to act in new ways or improve productivity. Acquiring knowledge and skills is one of the greatest motivating factors for VFTs. Knowledge and skills are acquired through training, exchange visits, and interaction with other farmers. But is 
Table 7 Number of times that the row option was ranked above the column option and significance levels of differences in ranks using Wald tests

\begin{tabular}{lllll}
\hline $\begin{array}{l}\text { Social } \\
\text { benefits }\end{array}$ & Exposure & $\begin{array}{l}\text { Gain } \\
\text { confidence }\end{array}$ & $\begin{array}{l}\text { Improved } \\
\text { social } \\
\text { status }\end{array}$ & $\begin{array}{l}\text { Increased } \\
\text { social } \\
\text { networks }\end{array}$ \\
\hline $\begin{array}{l}\text { Exposure } \\
\text { Gaining }\end{array}$ & - & 50 & 65 & 63 \\
$\quad \begin{array}{c}\text { confidence } \\
\text { Improved }\end{array}$ & $34 * * *$ & $40 * *$ & - & 53 \\
$\quad \begin{array}{l}\text { social } \\
\text { status }\end{array}$ & & & 59 & 40 \\
$\begin{array}{l}\text { Increased } \\
\text { social } \\
\text { networks }\end{array}$ & $36 * *$ & 46 & 59 & - \\
\hline
\end{tabular}

Significance level: $* p<0.10, * * p<0.05, * * * p<0.01$

acquiring knowledge and skills an investment in human capital? According to David and Asamoah (2011) if it improves productivity, agricultural innovation, income, and health, then it is an investment. The knowledge and skills VFTs have gained have enabled them to improve production on their farms in terms of the milk quality and quantity, which in turn increases their income. Other outcomes of acquiring knowledge and skills are improved household health, which results from more milk consumption at the household level and better returns from the farm as a result of the better utilization of resources for maximum profits. VFTs use improved homegrown feeds as a substitute for concentrates on their farms, thus reducing their production costs. Their knowledge and skills, which they share with other farmers, has, according to VFTs, also improved the living standards of the community.

\section{Social capital}

Social capital is an asset that is produced when people interact, creating relationships of trust and common understanding (Gotschi et al. 2008). Disseminating livestock feed technologies to other farmers enables VFTs to build social capital. According to Sobel (2002) social capital describes circumstances in which individuals can use membership in groups and networks to secure benefits (Putnam et al. 1993) and Coleman (1990) in contrast, define social capital as the networks, norms, trust, and links of reciprocity that facilitate cooperation and coordination. To understand how voluntarism enables VFTs to create social capital, we need to recognize the fact that social capital according to Bourdieu (1986) is an attribute of an individual in a social context. One can acquire social capital through social actions and can transform it to social benefits. VFTs belong to DMGs, which form DFBAs. The DFBAs are the highest management organ of the cooperative societies where farmers market their milk. VFTs are selected by their DMGs in collaboration with the DFBAs. They conduct their training within their DMGs and other groups outside their villages. Therefore, for VFTs, being a member of a DMG is itself an asset, as it is through DMGs that they are selected to be VFTs. Because VFTs are selected by their group members, their obligation is to the DMG and DFBA. The very notion of social capital presupposes a trusting relationship where group members use trust as a means of ensuring the VFT meets his/her obligation. Trust encompasses confidence, knowledge of the person's ability to train other farmers, and the belief and faith that the person will deliver. VFTs, however, are motivated by the benefits they anticipate receiving or are already receiving. These benefits manifest themselves in different forms of social capital. These manifestations are in the form of, for example, VFTs gaining confidence as a result of continuous training and the fact that their efforts are recognized. "When I see the farmers I have trained increase their milk production, I get the confidence to train more farmers, because it is a sign that my work is bearing fruit."

Other benefits are increased social networks through social interaction with farmers, extension providers, traders (input suppliers), and even donors. Other benefits that are intrinsic to farmers are the satisfaction and recognition brought about as a result of seeing farmers in the community employ the new technologies. Other manifestations of social capital are popularity and fame, which enhance VFTs' social status in the community. Enhanced social status is an important asset to VFTs, as it is seen to be a springboard to leadership positions in the future. Another manifestation of social capital is through altruism. Altruism is one of the main drivers that motivates farmers to engage in voluntarism. French philosopher Auguste Comte coined the word altruisme in 1851. He believed that the only moral acts were those intended to promote the happiness of others. VFTs are of the conviction that by training others to use improved practices, the standards of living within the community will improve. But some help others not only for the sake of altruism but also to protect themselves. This is a question posed by one of the VFTs: "If you have food and your neighbor does not have [food], he will steal it from you. So why not impart skills that can help everyone?" The benefits of altruism include satisfaction, which is a result of seeing their efforts of training others bearing fruit. Altruism among VFTs in Kenya is both cultural and biblical (being your brother's keeper) and hence the desire to improve the community at large. Kenyan society is highly religious. Many people believe that when you share what you have, be it knowledge or material things, one is blessed significantly by God. Additionally, altruism is rooted in the African culture, whereby the spirit of sharing is one of the 
philosophies of being humane (referred to as " $u t u$ " in Kiswahili). Altruism is also about reciprocity. VFTs disseminate livestock feed technologies believing that someday their deeds will be reciprocated by other group members: "Today I am a trainer on livestock feed technologies. My neighbor may be a trainer tomorrow on another aspect."

\section{Financial capital}

This study has shown that although VFTs incur costs such as transport and cell phone use when undertaking their training activities, they also receive in return direct and indirect financial benefits that motivate them. They are given seed for their demonstration plots and have the liberty to harvest and sell seed to other farmers within the community. In addition to selling seed, they diversify their income by taking advantage of the knowledge and skills gained to provide specialized services at a fee. These include being contracted by other farmers for silage making, hay baling, ear tagging, and dehorning. Those who have chaff cutters rent them out to others at a fee. NGOs also contract experienced VFTs to train groups at a fee. All these activities have increased VFTs income and remain a great motivator.

\section{Conclusion}

This article has examined the rationale of smallholder farmers volunteering their time and resources to train other farmers without pay. The findings have illustrated that examining voluntarism requires an understanding of the broader picture; that is, looking at issues with a wider lens. At face value, it appears that VFTs volunteer for purely altruistic reasons; however, that is not necessarily true in all the cases. Findings from this study have shown that even purely altruistic reasons do pay off in the long run. The payoff comes in both non-monetary and monetary forms. Non-monetary forms include different types of social capital such as personal satisfaction, reciprocity, recognition, gaining confidence, increased social networks, and enhanced social status through fame and popularity. Furthermore, the act of voluntarism is influenced not only by personal and community interests, but also by strong cultural and religious beliefs. Only through a combination of formal and informal methods of data collection will these issues be understood in depth. Monetary benefits include the sale of seed, seedlings, vines, and charging for services such as chaff cutter rental, silage making, and hay baling. Concerning gender, women had slightly higher mean scores for certain motivations such as altruism, income, and meeting the increased demand for training. However, differences between men and women were not statistically significant.

The study has illustrated that the initial investment that VFTs make in terms of time and resources training farmers pays off in the long run. The payoff is in the form of human, social, and financial capital that is nurtured or built in the course of their dissemination and training activities. These three types of assets are, therefore, key to sustaining voluntary farmer-to-farmer extension programs. Without these investments, voluntary farmer-to-farmer extension programs might not be sustained beyond the project's lifespan. What is critical, therefore, is to keep VFTs motivated; the greatest motivators are gaining knowledge and skills, altruism, social benefits, and income from selling inputs and services. Lukuyu et al. (2012) has shown that VFTs in western Kenya have continued training other farmers three years after the project supporting them ended. Social and income-generating activities were important factors that ensured sustainability of the approach in western Kenya. The key message from this study, which is applicable to other similar programs in the region, is that VFTs can work effectively without being paid for their services. But for farmer-to-farmer extension programs to be sustainable, VFTs need to be encouraged and supported to invest in human, social, and financial capital. Such support as suggested by VFTs could be in the form of providing incentives such as more training and exchange visits which enhance their knowledge and skills as well as giving them exposure, an important social benefit judging by the results herein (Kiptot and Franzel 2012). Giving VFTs opportunities to sell inputs and services is also an important incentive. Giving VFTs opportunities for exposure and certificates, bags, T-shirts, and caps for recognition may be just as important an ingredient as gaining knowledge and skills in laying the foundation for sustainable farmer-led extension programs.

Finally, the findings of this study and from the literature show that the general reasons that motivate volunteers are driven by personal and community interests, irrespective of the subject matter and context. However, the specific motivations critical to successful VFT programs are likely to be context specific; they may vary considerably in different settings. However, lessons learned here can be applicable to other volunteer programs in other sectors in the region. Research to understand how the specific motivations vary will help provide insight into the circumstances in which the approach is likely to work best, and how it can be modified to improve its effectiveness in reaching greater numbers of farmers.

Acknowledgments The authors are grateful to the Food Africa Program for financial support. We are grateful for the support of the 
EADD Project and two CGIAR Research Programs: Policies, Institutions and Markets; and Forests, Trees and Agroforestry. We also thank Patrick Mudavadi, Esther Karanja, and Sylvia Wafula for providing logistical support in the field, the enumerators who participated in this survey for their assistance in data collection, and Noah Oyembo for data entry. We wish to thank all the VFTs who made this study possible, Leroy Mwanzia for advice on the BradleyTerry Model, Kathy Sinclair for editing this article, and three anonymous reviewers who provided us with valuable comments.

\section{References}

Amudavi, D.M., Z.R. Khan, J.M. Wanyama, C.A.O. Midega, J. Pittchar, and I.M. Nyangau. 2009. Assessment of technical efficiency of farmer teachers in the uptake and dissemination of push-pull technology in Western Kenya. Crop Protection 28: 987-996.

Bourdieu, P. 1986. The forms of capital. In Handbook of theory and research for the sociology of education, ed. J.G. Richardson, 241-258. New York: Greenwood.

Bradley, R.A., and M. Terry. 1952. The rank analysis of incomplete block designs:i the method of paired comparisons. Biometrika 39: 324-345.

Chambers, R., and G. Conway. 1992. Sustainable rural livelihoods: practical concepts for the $21^{\text {st }}$ century. IDS Discussion Paper 296. Brighton, U.K. Institute of Development Studies.

Christoplos, I. 2010. Mobilizing the potential of rural and agricultural extension. Rome, Italy: Office of Knowledge Exchange, Research and Extension, Food and Agricultural Organization of the United Nations and Global Forum for Rural Advisory Services.

Coleman, J. 1988. Social capital in the creation of human capital. American Journal of Sociology 94: 95-120.

Coleman, J. 1990. Foundations of social theory. Cambridge: Harvard University Press.

David, S., and C. Asamoah. 2011. The impact of farmer field schools on human and social capital: a case Study from Ghana. Journal of Agricultural Education and Extension 17(3): 239-252.

Davis, K. 2008. Extension in sub-Saharan Africa: overview and assessment of past and current models and future prospects. Journal of International Agricultural and Extension Education 15(3): 15-28.

De Haan, N. 2001. Of goats and groups: a study on social capital in development projects. Agriculture and Human Values 18: 71-84.

Gautam, M. 2000. Agricultural extension: the Kenya experience. an impact evaluation. Washington, DC: The World Bank.

Gilbert, R.A., W.D. Sakala, and T.D. Benson. 2002. Gender analysis of a nationwide cropping system trial survey in Malawi. African Studies Quarterly 6(1). http://web.africa.ufl.edu/asq/v6/v61a9. htm. Accessed 28 May 2010.

Gotschi, E., J. Njuki, and R. Delve. 2008. Gender equity and social capital in smallholder farmer groups in Mozambique. Development in Practice 18(4/5): 650-657.

Hawkensworth, S., and J.D. Garcia Perez. 2003. Potentials and constraints of the farmer-to-farmer programme for environmental protection in Nicaragua. Land Degradation and Development 14: $175-183$

Hellin, J., and J. Dixon. 2008. Operationalising participatory research and farmer-to-farmer extension: the Kamayoq in Peru. Development in Practice 18(4): 627-632.

Hellin, J., C. De la Torre, J. Coello, and D. Rodriguez. 2006. The Kamayoq in Peru: farmer-to-farmer extension and experimentation. LEISA magazine 22(3): 32-34.
Katungi, E., S. Klasen, and M. Smale. 2008. Gender, social capital and information exchange in rural Uganda. Journal of International Development 20: 35-52.

Kawash, K. 2009. Why volunteer? Peasant rationality re-examined: A study of what motivates farmers to volunteer in Malawi. Master Thesis. Lund University, Sweden.

Kiptot, E. 2007a. Seeing beyond fertiliser trees. A case study of a community based participatory approach to agroforestry research and development in western Kenya. Published PhD thesis. Wageningen University and Research Centre, Wageningen, Netherlands.

Kiptot, E. 2007b. Eliciting indigenous knowledge on tree fodder among Maasai pastoralists via a multi-method sequencing approach. Agriculture and Human Values 24(2): 231-243.

Kiptot, E., and S. Franzel. 2012. Effectiveness of the farmer-trainer approach in dissemination of livestock feed technologies: A survey of volunteer farmer trainers in Kenya. Nairobi: World Agroforestry Centre.

Kiptot, E., S. Franzel, P. Hebinck, and P. Richards. 2006. Seed and knowledge sharing: farmer-to-farmer dissemination of agroforestry technologies in western Kenya. Agroforestry Systems 68: $167-179$.

Kirui, J., and S. Franzel. 2012. East Africa Dairy Development Project Semi-Annual Report (January-June 2012). Nairobi: World Agroforestry Centre.

Kirui, J., S. Franzel, and B. Lukuyu. 2009. Farmer trainers: An emerging dissemination pathway. Nairobi: Poster presented at the World Agroforestry Congress.

Lenoir, M. 2009. Farmers teaching farmers. ICT Update Issue 52. CTA, Wageningen, Netherlands.

Lukuyu, B., F. Place, S. Franzel, and E. Kiptot. 2012. Disseminating improved practices: are volunteer farmer trainers effective? Journal of Agricultural Education and Extension 18: 525-540.

Mazancovà, J., and B. Havrland. 2010. The role of motivation in extension services in the Bie Province (Angola). Agricultura Tropica et subtropica 43(3): 186-190.

Mulanda, J., E. Mwenya, and E. Namalambo. 2000. Draught animal power: Experiences of farmer training in the Northern communal areas of Namibia. In Empowering farmers with animal traction ed. P.G. Kaumbutho, R.A. Pearson, and T.E Simalenga, 303-306. Proceedings of the workshop of the Animal Traction Network for Eastern and Southern Africa (ATNESA). Mpumalanga, South Africa.

Nagel, J. 1997. Alternative approaches to organizing extension. In Improving agricultural extension: A reference manual, ed. B.E. Swanson, R.P. Bentz, and A.J. Sofranko. Rome: FAO.

Putnam, R., R. Leonardi, and R.Y. Nanetti. 1993. Making democracy work. Princeton: Princeton University Press.

Roy, K., and S. Ziemek. 2000. On the economics of volunteering. ZEF-Discussion Papers on Development Policy 31. Centre for Development Research, Bonn, Germany.

Scarbourough, V., S. Killough, D.A. Johnson, and J. Farrington (eds.). 1997. Farmer-led extension-concepts and practices. London: Intermediate Technology Publications.

Selener, D., J. Chenier, and R. Zelaya. 1997. Farmer-to-farmer extension-lessons from the field. New York: IIRR.

Sinja, J., J. Karugia, D.M. Mwangi, I. Baltenweck, and D. Romney. 2004. Adoption of fodder legumes technology through farmerto-farmer extension approach. Uganda Journal of Agricultural Sciences 9: 22-26.

Sobel, J. 2002. Can we trust social capital? Journal of Economic Literature 40: 139-154.

Uny, S. 2008. Factors and motivations contributing to community volunteers' participation in a nursery feeding project in Malawi. Development in Practice 18(3): 437-445. 
Wanyoike, F. 2001. Dissemination and adoption of improved fodder trees: The case of Calliandra calothyrsus in Embu District, Kenya. MSc Thesis. University of Nairobi, Kenya.

Weinand, J. 2002. Farmer-to-farmer extension: Opportunities and constraints of reaching poor farmers in southern Malawi. Masters Thesis. University of Hohenheim, Germany.

Ziemek, S. 2006. Economic analysis of volunteers' motivations: a cross-country study. Journal of Socio-Economics 35: 532-555.

\section{Author Biographies}

Evelyne Kiptot, $\mathbf{P h D}$ is a Social Scientist at the World Agroforestry Centre. She received her doctorate in Social Science from
Wageningen University, The Netherlands. Her research focuses on innovative extension approaches and gender issues in agroforestry adoption.

Steven Franzel, $\mathbf{P h D}$ is a Principal Agricultural Economist at the World Agroforestry Centre and leads the Centre's research on Rural Advisory Services. He holds a PhD in Agricultural Economics from Michigan State University, USA. His main research interests include farming systems, participatory research, extension approaches, and natural resource management. 